\title{
Hematological detraining-related changes among elderly individuals with high blood pressure
}

\author{
(iD) José M. Cancela $a^{1,2}$ \\ (D) Miguel A. Sanchez-Lastra ${ }^{1,2}$ \\ (iD Miguel Camôes ${ }^{3}$ \\ (iD) Pedro Bezerra ${ }^{3}$
}

1. HealthyFit Research Group, Department of Special Didactics, Faculty of Education and Sports Sciences, University of Vigo, Pontevedra, Spain. 2. Galicia Sur Health Research Institute (IIS Galicia Sur) Sergas-UVIGO, Spain. 3. Escola Superior de Desporto e Lazer Complexo Desportivo e de Lazer.

http://dx.doi.org/10.1590/1806-9282.66.8.1108

\section{SUMMARY}

AIM: The aim of the present study was to compare the effects of detraining on physical performance, blood pressure, biologic and anthropometric variables of hypertensive elderly individuals, grouped by two levels of previous physical activity.

METHODS: A total of 87 elderly individuals (70 to 93 years old) with systolic/diastolic blood pressure levels above $120 / 80 \mathrm{mmHg}$ who participated during 18 non-consecutive months in 2 years in physical exercise programs offered in northern Portugal communities were included in the study. Tests were performed before and after three months of no exercise. Attendance to the exercise sessions, hematological markers, cardiorespiratory function, and anthropometric variables were assessed. The results were analyzed according to the fulfillment of the WHO recommendations on moderate physical activity (at least 150 minutes/week).

RESULTS: Weight, total cholesterol, and glucose were influenced by the amount of physical activity performed previously to the detraining period. After the detraining period, the total cholesterol, glucose, insulin, and weight had significant differences influenced by the amount of physical activity previously performed $(p<0.05)$.

CONCLUSIONS: The number of minutes per week of aerobic and resistance exercise training over 18 non-consecutive months was not a significant determinant factor in the development of hypertension during the three months of detraining.

KEYWORDS: Aged. Quality of life. Exercise. Hypertension.

\section{INTRODUCTION}

Physical inactivity is regarded as the greatest public health problem of the $21^{\text {st }}$ century ${ }^{1}$ because of its high prevalence in the world population and associated problems. The negative effect of a sedentary lifestyle is associated with an increased risk of morbidity and worsening of many chronic diseases such as cardiovascular disease (CVD), congestive heart failure (CHF), stroke, osteoporosis, obesity, type 2 diabetes, some types of cancer and hypertension ${ }^{2}$. The many consequences of this problem led the World Health Organization $(\mathrm{WHO})^{3}$ in 2014 to set, within the 9 global non-communicable diseases (NCDs), targets for the year 2025, of which two were related to physical activity (PA). First, a relative reduction of $25 \%$ in premature mortality from cardiovascular diseases, cancers, and diabetes by 2025, in which PA plays an important role $^{4}$. Second, in Target 3, a 10\% relative reduction in the prevalence of insufficient physical activity. 
One of the most common health complications in which physical inactivity plays an important role is high blood pressure (HBP). A person is considered to have HBP when the systolic blood pressure (SBP) and diastolic blood pressure (DBP) are greater than 120 and $80 \mathrm{mmHg}$, respectively. A chronic or persistent increase of blood pressure (BP) can be classified as prehypertension (120-139/80-89 mm Hg) or arterial hypertension (AH) $(\geq 140 / 90 \mathrm{~mm} \mathrm{Hg})^{5}$. Prehypertension is already associated with an increased risk of cardiovascular diseases (CVD) ${ }^{6}$. Although age, male sex, and family history are non-modifiable risk factors for CVD, there are also other relevant factors, such as unhealthy eating habits (e.g. excessive salt consumption), smoking, and sedentarism, which can be prevented. Indeed, WHO's aims for 2025 focused also on a $30 \%$ relative reduction in the mean intake of salt/sodium (Target 4 ) and a $25 \%$ relative reduction in the prevalence of increased blood pressure (Target 5).

Scientific literature has reported the benefits of adapted physical exercise in patients with this health condition, demonstrating that a single session of aerobic exercise at an intensity of 50-100\% of $\mathrm{VO}_{2} \max$ produces a lowering of $18-20 \mathrm{~mm} \mathrm{Hg}$ in systolic and 7-9 $\mathrm{mm} \mathrm{Hg}$ in diastolic blood pressure ${ }^{7}$. These changes remain for 12-16 $\mathrm{h}$ after exercise, and the maximum changes in blood pressure have been observed in individuals with mild (Stage I) hypertension. Therefore, the promotion of healthy habits is especially important at this stage due to the frequently observed benefits in both prehypertensive and hypertensive patients ${ }^{7,8}$.

However, the authors understand that there is little knowledge demonstrated on how these and other AH related variables change when regular physical exercise is stopped over a period of time. Hence, the importance of knowing the extent to which the effects of physical exercise are sustained over time after suspension of exercise, and whether such detraining poses a risk to individuals.

Therefore, the aim of the present study was to compare the effects of detraining on physical performance, blood pressure, biologic and anthropometric variables of hypertensive elderly individuals, grouped by two levels of previous physical activity.

\section{METHODS}

\section{Participants}

The sample was taken from an already published study with a high number of participants ${ }^{9}$. A total of
87 elderly individuals aged between 70 and 93 years were recruited from several cities in the region of Minho in Portugal, where the city council offered physical exercise programs for the elderly in municipal sports centers.

The inclusion criteria were: (a) Levels of SBP/DBP $>120 / 80 \mathrm{~mm} \mathrm{Hg}$ at the end of the exercise programs; (b) voluntary participation and signing of written informed consent. All individuals with BP lower than the aforementioned and those who had declined voluntary participation were excluded from the study.

\section{Procedure}

All potential participants who met the inclusion criteria were first informed about the study characteristics and protocol. Then, they were asked to sign a written informed consent prior to participation. The study was approved by the Scientific Council's Ethics Committee of the Polytechnic Institute of Viana do Castelo and was carried out in accordance with the Declaration of Helsinki Standards (World Medical Association, 2013), following the European Community guidelines for Good Clinical Practice (111/3976/88, July 1990).

A general clinical interview and a fitness test were conducted, besides obtaining data on attendance to the exercise programs, as well as anthropometric and biochemical variables.

In order to analyze detraining effects, variables were analyzed in the last month of training: June (TO) prior to finishing the exercise program, and after physical inactivity for three months, in October (T1), during the first month of activity. During this period, participants led a normal life and did not participate in said exercise programs. The researchers who analyzed the data were blinded to the amount of physical activity carried out by the subjects.

\section{Assessment}

The Six-Minute Walking Test (6MWT) was used to assess the physical condition in terms of cardiovascular function. This test is an amendment to the original Cooper's 12-Minute Walk-Run Test ${ }^{10}$ and evaluates the maximum distance a person is able to walk in 6 minutes. It is widely used in people with cardiovascular or pulmonary diseases and it has been proven to be a good predictor of peak oxygen consumption $\left(\mathrm{VO}_{2} \mathrm{max}\right)$ and survival in patients with heart failure $(\mathrm{r}=0.64 ; \mathrm{p}<0.001)^{11}$.

Blood samples were obtained after a minimum of eight hours of fasting, with the subject in a 
sitting position, using standard clinical laboratory methods. Serum variables were measured with COBAS 711 and 6000 analyzers (Roche Diagnostics, Mannheim, Germany) and included glycated hemoglobin (HbA1c), cholesterol (HDL, LDL and total), triacylglycerol, blood glucose, insulin, and D-Vitamin levels.

The anthropometric variables analyzed were weight (Tanita BC-418 Body Composition Analyser, Tanita Corporation, Tokyo, Japan), height (Seca 202 Measuring Rod, Seca Gmbh \& Co, Hamburg, Germany), and Body Mass Index (BMI). Evaluation of SBP and DBP was done with an electronic sphygmomanometer (Omron M6, Omron Healthcare Group, Kyoto, Japan) following the recommendations from international guidelines.

\section{Exercise program}

The exercise program carried out comprised fitness exercises from Monday to Saturday, with 50 minutes/week sessions held in the mornings over 9 months of the year. The sessions were supervised by Physical Education graduates, wherein exercises had a (65\%) aerobic component and included lower limb strengthening exercises (35\%), performed at moderate intensity. The program was carried out over a two-year period, in 18 non-consecutive months.

\section{Statistical analysis}

For statistical analysis of the results, subjects were divided into two groups depending on whether the amount of workout in minutes/week was higher $(G>150)$ or lower $(G<150)$ than 150 minutes/week, which is a cut-off point based on the WHO recommendations ${ }^{3}$. Data analysis was divided into two parts. The first part consisted of a descriptive analysis of the study sample based on the frequency of physical exercise per week ( $<150 \mathrm{~min} /$ week; $\geq 150$ $\mathrm{min} /$ week). The Kolmogorov-Smirnov test was used to verify the normality $(p>0.005)$ of the variables studied. The Student's t-test was used for independent data, both at TO and T1, in order to establish the presence or absence of differences between the two groups. Subsequently, an inferential covariance analysis (ANCOVA 2X2) was performed with the following covariates: age, sex, and education level. A p-value $<0.05$ was considered significant. The SPSS Statistical package 20.0 for Windows (IBM Corp., Armonk, N.Y., USA) software was used for statistical analysis.

\section{RESULTS}

A total of 87 participants (69.4\% female and 30.6\% male) completed the follow-up phase carried out at the end of the exercise program, during which the average age of the sample was $78.5 \pm 2.6$ years.

\section{Start of the follow-up}

Table 1 shows the values of the physical variables, blood pressure, and complete blood count (CBC) at the start of the follow-up. Data are categorized by minutes of physical activity per week. No significant differences in SBP and DBP were observed between the two groups. However, the G $>150$ presented SBP values considered as high-normal (130-139 mm Hg) while the average values in $\mathrm{G}<150$ exceeded $140 \mathrm{~mm}$ $\mathrm{Hg}$, which is considered as Stage 1 hypertension. DBP values were optimal $(<80 \mathrm{~mm} \mathrm{Hg})$ in both groups. In the remaining variables, significant differences were seen only in weight, BMI, and in the distance covered in the 6MWT test, in which BMI presented lower values while more distance was covered in the $6 \mathrm{MWT}$, in the $\mathrm{G}>150$.

As far as cardiovascular risk factors (CRF) are concerned, despite total cholesterol in both groups being higher than $190 \mathrm{mg} / \mathrm{dL}$, the LDL, HDL, or triglyceride levels did not reach values that indicate the presence of dyslipidemia. On the other hand, the fasting plasma glucose in both groups was higher than $102 \mathrm{mg} / \mathrm{dL}$, values considered as CRF (102-125 mg/dL) . Moreover, in the $\mathrm{G}<150$ group, the BMI was higher than $30 \mathrm{~kg} / \mathrm{m}^{2}$. A second evaluation was performed after the 3-month inactivity period (detraining). Significant differences were found between the groups: the total distance covered in 6MWT and vitamin D levels were higher, while the total cholesterol, triglycerides, and insulin were lower in the $\mathrm{G}>150$ as compared to the $\mathrm{G}<150$ (Figure 1).

Table 2 shows a comparative analysis of the two evaluation times (TO and T1) for the two groups. Significant differences were found in the development of some variables for $\mathrm{T} 0$ and $\mathrm{T} 1$ in both groups. These differences were lower weight gain $(p=0.010)$ and BMI $(p=0.002)$ in the $G<150$ versus the $G>150$, as well as a decrease in total cholesterol $(p=0.003)$ in the $\mathrm{G}>150$ compared to an increase in the $\mathrm{G}<150$, a further reduction in HDL-cholesterol levels $(p=0.023)$ in the $G>150$ versus the $G<150$, a slight increase in glucose $(p=0.046)$ in the $G>150$ versus the $G<150$ and a greater increase in insulin $(p=0.004)$ in the $\mathrm{G}>150$ versus the $\mathrm{G}<150$. 
TABLE 1. ANTHROPOMETRIC, PHYSICAL PERFORMANCE, BLOOD PRESSURE, AND BIOCHEMICAL VARIABLES AFTER 18 NON-CONSECUTIVE MONTHS OF EXERCISE TRAINING IN SUBIECTS EXERCISING $<150$ OR $\geq 150$ MINUTES PER $\operatorname{WEEK}(\mathrm{N}=87)$.

\begin{tabular}{|c|c|c|c|c|c|c|}
\hline & & & \multicolumn{4}{|c|}{ Amount of exercise } \\
\hline & \multicolumn{2}{|l|}{$\begin{array}{l}\text { Total } \\
\mathrm{n}=87\end{array}$} & \multicolumn{2}{|c|}{$\begin{array}{l}<150 \mathrm{~min} / \text { week } \\
\mathrm{n}=41\end{array}$} & \multicolumn{2}{|c|}{$\begin{array}{l}\geq 150 \mathrm{~min} / \text { week } \\
\mathrm{n}=46\end{array}$} \\
\hline & Mean & Sd & Mean & Sd & Mean & Sd \\
\hline Age (years) & 78.5 & 2.6 & 78.3 & 2.4 & 78.6 & 2.7 \\
\hline Sex (n Female) & 60 & & 28 & & 32 & \\
\hline Frequency (n/week) & 3.3 & 0.9 & 1.6 & 0.5 & 5.1 & 1.3 \\
\hline \multicolumn{7}{|l|}{ Physical variables } \\
\hline Weight (kg) & 69.9 & 11.7 & 73.4 & 11.7 & 66.3 & $10.4^{*}$ \\
\hline Height $(\mathrm{cm})$ & 155.7 & 8.2 & 156.0 & 8.6 & 155.3 & 7.3 \\
\hline $\mathrm{BMI}\left(\mathrm{kg} / \mathrm{m}^{2}\right)$ & 28.8 & 4.1 & 30.3 & 5.0 & 27.4 & $3.4^{*}$ \\
\hline Total distance walked in 6 minutes $(\mathrm{m})$ & 408.8 & 122.7 & 360.2 & 144.2 & 457.5 & $101.1^{* \star}$ \\
\hline \multicolumn{7}{|l|}{ Blood Pressure } \\
\hline Systolic Blood Pressure (mmHg) & 139.2 & 21.3 & 141.9 & 14.9 & 136.5 & 15.5 \\
\hline Diastolic Blood Pressure $(\mathrm{mmHg})$ & 73.9 & 10.0 & 74.8 & 9.1 & 73.0 & 8.3 \\
\hline \multicolumn{7}{|l|}{ Blood-count } \\
\hline Glycosylated Hemoglobin (\%) & 6.1 & 1.0 & 5.8 & 0.7 & 6.3 & 1.3 \\
\hline Cholesterol total (mg/dL) & 198.1 & 44.3 & 200.9 & 33.6 & 193.3 & 43.3 \\
\hline Cholesterol HDL (mg/dL) & 62.8 & 19.2 & 62.9 & 14.2 & 62.6 & 25.6 \\
\hline Cholesterol LDL (mg/dL) & 109.3 & 41.1 & 109.0 & 39.3 & 109.7 & 36.4 \\
\hline Triacylglycerol (mg/dL) & 125.3 & 47.8 & 145.3 & 141.0 & 105.3 & 55.0 \\
\hline Glucose (mg/dL) & 108.9 & 29.5 & 102.1 & 16.7 & 115.7 & 37.7 \\
\hline Insulin $(\mu \mathrm{UI} / \mathrm{mL})$ & 7.1 & 3.3 & 6.9 & 3.0 & 7.2 & 3.3 \\
\hline D-Vitamin $(\mathrm{OH} 25)(\mathrm{ng} / \mathrm{mL})$ & 15.9 & 7.4 & 17.6 & 7.8 & 14.2 & 7.2 \\
\hline
\end{tabular}

$* p<0.05 ; * p<0.001$

TABLE 2. TIME X GROUP INTERACTION ANALYSIS.

\begin{tabular}{|c|c|c|c|}
\hline & \multicolumn{2}{|c|}{ Mean difference from Baseline $(95 \% \mathrm{CI})$} & \multirow{2}{*}{$\begin{array}{l}\text { Factor Moment x Group } \\
\text { p-Value ANCOVA }\end{array}$} \\
\hline & $\begin{array}{l}<150 \mathrm{~min} / \text { week } \\
\mathrm{n}=41\end{array}$ & $\begin{array}{l}\geq 150 \mathrm{~min} / \text { week } \\
\mathrm{n}=46\end{array}$ & \\
\hline Weight (kg) & $0.6(-1.8$ to 1.6$)$ & $5.3(3.0$ to 7.6$)$ & $F_{2^{\prime} 85}=6.125 ; p=0.010$ \\
\hline Height $(\mathrm{cm})$ & $-0.4(-0.8$ to 0.1$)$ & $-0.1(-0.8$ to 0.6$)$ & $F_{2^{\prime} 85}=3.198 p=0.161$ \\
\hline $\mathrm{BMI}\left(\mathrm{kg}\left(\mathrm{m}^{2}\right)\right.$ & $0.1(0.9$ to -0.7$)$ & $2.2(-0.0$ to 4.5$)$ & $F_{2}, 85=8.695 ; p=0.002$ \\
\hline Total distance walked in 6 minutes $(\mathrm{m})$ & $-36.1(-16.4$ to 55.7$)$ & $-31.0(-11.0$ to -50.9$)$ & $F_{2 \prime 85}=1.222 p=0.675$ \\
\hline Sistolic Blood Pressure $(\mathrm{mmHg})$ & $3.7(-7.2$ to 14.7$)$ & $6.0(-0.5$ to 12.5$)$ & $F_{2^{\prime} 85}=1.879 p=0.456$ \\
\hline Diastolic Blood Pressure $(\mathrm{mmHg})$ & $2.0(-2.2$ to 6.4$)$ & $1.6(-0.6$ to 3.8$)$ & $F_{2185}=2.058 p=0.321$ \\
\hline Glycosylated Hemoglobin (\%) & $0.1(-0.1$ to 0.3$)$ & $-0.3(-0.0$ to -0.6$)$ & $F_{2 \prime 85}=3.214 p=0.111$ \\
\hline Cholesterol total (mg/dL) & $12.6(-2.6$ to 27.9$)$ & $-1.2(-7.1$ to 9.6$)$ & $F_{2^{\prime} 85}=7.621 p=0.003$ \\
\hline Cholesterol HDL (mg/dL) & $-0.3(-0.2$ to -0.8$)$ & $-4.5(-2.4$ to -6.5$)$ & $F_{2,85}=4.698 p=0.023$ \\
\hline Cholesterol LDL (mg/dL) & $10.4(2.0$ to 18.8$)$ & $1.1(-1.5$ to 3.7$)$ & $F_{2 \prime 85}=1.789 p=0.210$ \\
\hline Triacylglycerol (mg/dL) & $-11.1(-1.6$ to 23.8$)$ & $-14.1(14.7$ to -42.9$)$ & $F_{2^{\prime} 85}=2.221 p=0.581$ \\
\hline Glucose (Jujum) (mg/dL) & $12.8(10.6$ to 14.9$)$ & $6.9(-9.3$ to 23.1$)$ & $F_{2^{\prime} 85}=1.879 p=0.459$ \\
\hline Insulin $(\mu \mathrm{UI} / \mathrm{mL})$ & $1.4(-0.3$ to 3.1$)$ & $5.0(-1.6$ to 8.3$)$ & $F_{2,85}=6.657 ; p=0.004$ \\
\hline D-Vitamin $(\mathrm{OH} 25)(\mathrm{ng} / \mathrm{mL})$ & $1.3(-1.7$ to 4.2$)$ & $-0.6(-1.8$ to 3.0$)$ & $F_{2,85}=3.874 ; p=0.326$ \\
\hline
\end{tabular}

Repeated measures for the ANCOVA analysis and analysis of variance F tests were used. Covariates included age, sex, education level.

\section{DISCUSSION}

The aim of the present study was to compare the effects of detraining on physical performance, blood pressure, biologic and anthropometric variables of hypertensive elderly individuals, grouped by two levels of previous physical activity. They participated in a 2-year physical exercise program promoted by different city councils in the North of Portugal. The analysis 
FIGURE 1. ANALYSIS OF BIOCHEMICAL VARIABLES IN THE GROUPS <150MIN/WEEK AND $\geq 150$ MIN/WEEK (AFTER TRAINING - DETRAINING).

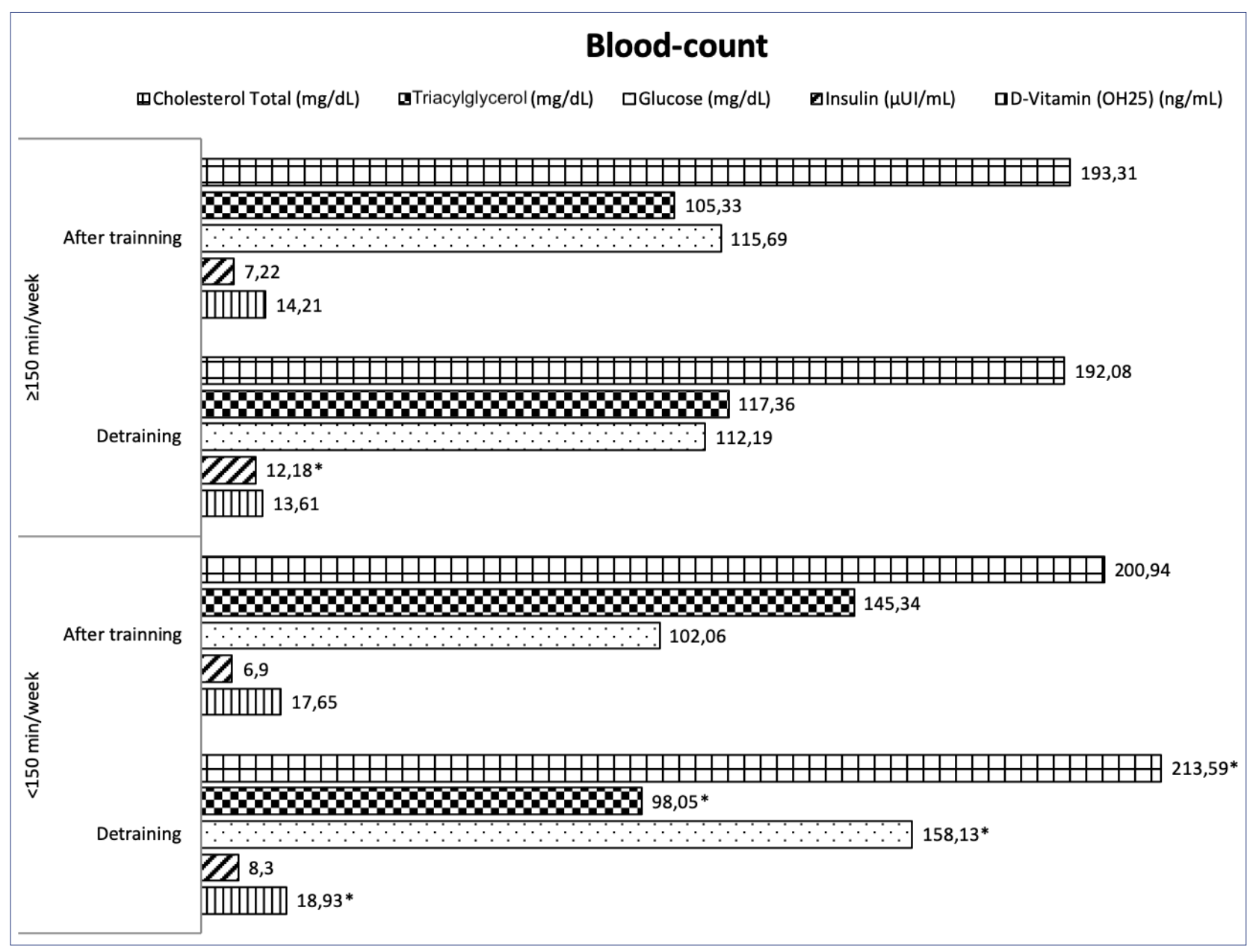

${ }^{*} \mathrm{p}<0.05$

was carried out three months after completion of the program and focused on the number of exercise minutes per week.

Numerous studies have documented the usefulness of physical exercise for reducing cardiovascular risk factors, among which is $\mathrm{HBP}^{12,13}$. The mechanism involved seems to be the reduction of arterial stiffness due to physical exercise by increasing serum levels of nitric oxide (determinant factor in endothelial relaxation), and also by producing adropine, whose levels increase with exercise ${ }^{14}$.

The findings from our study are of special relevance for several reasons. Firstly, studies that have analyzed the effects of physical exercise on SBP/DBP in different population groups did not regularly report on any follow-up periods after the intervention, which may be a limitation for studying the residual effects of detraining on these variables ${ }^{7}$. This study intends to provide relevant information on this issue. Secondly, the follow-up periods subsequent to physical exercise programs with a duration greater than 6 or 12 months are even less analyzed. Cornelissen and Smart ${ }^{7}$, in their systematic review and meta-analysis, reported that prolonged exercise programs of more than 6 months were associated with a lower reduction in BP values than those of shorter duration. They suggest that this may be due to longer programs having fewer supervised sessions, and hence lower attendance at sessions. Therefore, in order to analyze the residual effects of exercise on subjects that participated routinely in the programs, this study focused on the number of minutes per week, representative of the adherence to the exercise sessions. Thirdly, as indicated by Cornelissen and Smart ${ }^{7}$, there are very few studies that have actually carried out combined physical exercise programs, and our study is one such example. Moreover, recent research indicates that the effects of combined strength and cardiovascular endurance programs may produce better results than programs that focus only on a single physical capacity ${ }^{12,13,15}$. 
Participants were initially assessed after completing the exercise programs and significant differences were only found between groups in the 6MWT and in their weight. The $\mathrm{G}<150$ presented a higher weight, BMI $>30 \mathrm{~kg} / \mathrm{m}^{2}$, considered as obesity level I, and its relationship with physical activity is unmistakable ${ }^{4}$. Literature also indicates that weight reduction is associated with a higher reduction in SBP and SDP values $^{7}$. There was no significant difference between groups for SBP. In the G>150 group, average values did not reach the cut-off point established for Stage 1 hypertension (SBP/DBP $\geq 140 \mathrm{~mm} \mathrm{Hg}$ ); however, this did happen in the $G<150$ group. The effect that the more physical exercise the better the BP has been amply demonstrated in the literature, hence this situation is probably influenced by the previous physical activity levels ${ }^{7}$. Another important aspect worth mentioning is that exercise intensity has been identified as a determinant factor for reducing $\mathrm{BP}^{7}$. Therefore, the present study groups were engaged in exercise programs of similar intensity, duration, and type, the only difference being in the program carried out, the frequency per week, and consequently the accumulated physical exercise in minutes/week. This is why the present results are exempt from this influence. After a 3-month detraining period, no significant SBP/ DBP differences were found in any of the groups or in the analysis of interaction time/group. There is nevertheless an increasing trend in it, which is more pronounced in the $\mathrm{G}>150$. The authors feel that this rebound effect of BP recovery conditioned by the amount of physical exercise performed has not been reported previously ${ }^{7}$. One of the explanations could be related to the increase in weight and BMI after the detraining period, which was more pronounced in the $\mathrm{G}>150$ compared to the $\mathrm{G}<150$. Considering that BMI has been positively associated with $\mathrm{BP}^{16}$, it is reasonable to think that the increase in BMI could have influenced the increase of $\mathrm{BP}$ in the $\mathrm{G}>150$. Nevertheless, more research is needed in order to identify how this or other parameters, such as the previous levels of physical activity, could influence this rebound effect.

In terms of the $6 \mathrm{MWT}$, at baseline, the $\mathrm{G}>150$ group covered more distance in the 6MWT, something expected due to the widely documented relationship between the test and the amount of physical activity undertaken ${ }^{17,18}$. The distance covered by both groups in this test was lower than that reported by Araújo et al. ${ }^{19}$ in the Portuguese high BP population with an average age of 71 years. The differences in the results of the 6MWT may be because the average age in our sample was higher than that in Araújo et al. ${ }^{19}$ (78 years vs. 71 years), and the average BMI value in our sample was higher. Both these factors have been established as influential in the results of the $6 \mathrm{MWT}^{20}$. After the three months of detraining, significant differences were again observed in terms of higher total distance covered in the test, but no significant differences were identified in the analysis of interaction time/group. This indicates a trend towards greater maintenance of physical activity-related functional capacity after a detraining period. These results are in line with those reported by other studies ${ }^{21}$, considering that health condition is a determining factor in the results of the $6 \mathrm{MWT}^{22}$ and that the $\mathrm{G}<150$ group had higher BP values.

The relationship between the cumulative level of physical activity and its influence on other biochemical variables is well documented in the literature and is present in the remaining variables, where significant differences were observed in the case of low total cholesterol (significantly higher in the $\mathrm{G}<150$ ), as well as in triglycerides ${ }^{23}$. A lower increase in glucose level was observed in the $\mathrm{G}>150$ group compared with the $\mathrm{G}<150$, and results are in line with other studies ${ }^{24}$. Given that there was no nutritional intervention and assuming that eating habits did not change in the participants, the explanation for the high D-vitamin concentration is perhaps because the baseline evaluation (start of the follow-up) was carried out before the summer, while the second evaluation was performed later, hence the higher exposure to UVB rays. The differences between the groups could be due to the fact that participants who did more activity were outdoors in sunlight during the three months of follow-up, and the vitamin $\mathrm{D}$ concentration can also be related to the level of physical activity ${ }^{25}$.

Even though the findings from this study may be of relevance for the reasons outlined above, there are still a number of limitations that need to be considered. In the first place, we were unable to obtain data prior to the exercise program, which would have facilitated analysis of their development and better contextualization of the differences between both groups during the follow-up period. Secondly, no information was collected on whether participants smoked or not, and the amount of tobacco consumed during the study period.

In conclusion, the number of minutes per week of aerobic and resistance exercise training over 18 
non-consecutive months was not a significant determinant factor in the HBP development during the three months of detraining after a 2-year exercise program in the sample of 87 elderly HBP individuals aged 70 to 93 years. However, other variables such as weight, total cholesterol, and glucose may be influenced by the amount of physical activity undertaken and thus have a protective effect at a cardiovascular level in this population.

\section{Funding}

This research was supported by FEDER Funds through the Competitive Factors Operational Program-COMPETE and by National Funds through the FCT-Foundation for Science and Technology within the scope of the project State of Health and
Physical Activity of the Elderly Population: PTDC/ DTP-DES/0209/2012.

\section{Author's Contribution}

José M. Cancela contributed to the design, conceptualization, data analysis, and supervised the writing. Miguel A. Sanchez-Lastra contributed to the design, conceptualization, and data collection. Miguel Camôes contributed to the design, conceptualization, and data collection. Pedro Bezerra contributed to the design, conceptualization, and data collection.

This work was conducted in the Escola Superior de Desporto e Lazer Complexo Desportivo e de Lazer Comendador Rui Solheiro, Melgaço (Portugal).

\section{RESUMO}

OBJETIVO: O objetivo do presente estudo foi comparar os efeitos da desvalorização do desempenho físico, da pressão arterial e das variáveis bioquímicas e antropométricas dos idosos hipertensivos, dependendo de duas categorias de atividade física prévia.

MÉTODOS: Foram incluídos no estudo 87 idosos (70 a 93 anos) com níveis de pressão arterial sistólica/diastólica superiores a 120/80 $\mathrm{mmHg}$ que participaram durante 18 meses não consecutivos em dois anos em programas de exercício físico. Os testes foram realizados antes e depois de três meses sem programas de exercícios. Foram avaliados a frequência das sessões de exercício, marcadores hematológicos, função cardiorrespiratória e parâmetros antropométricos. Os resultados foram analisados de acordo com o cumprimento das recomendações da OMS sobre atividade física moderada (pelo menos 150 minutos/semana).

RESULTADOS: O peso, o colesterol total e a glicose foram influenciados pela quantidade de atividade física realizada previamente ao período de destreinamento. Posteriormente, o colesterol total, a glicose, a insulina e o peso apresentaram diferenças significativas influenciadas pela quantidade de atividade física previamente realizada $(p<0,05)$.

CONCLUSÕES: O número de minutos por semana de treinamento aeróbico e de exercícios resistidos durante 18 meses não consecutivos não foi um fator determinante significativo na evolução da hipertensão durante os três meses de destreinamento.

PALAVRAS-CHAVE: Idoso. Qualidade de vida. Exercício. Hipertensão.

\section{REFERENCES}

1. Blair SN. Physical inactivity: the biggest public health problem of the $21^{\text {st }}$ century. Br J Sports Med. 2009;43(1):1-2

2. Kesaniemi $Y K$, Danforth EJ, Jensen MD, Kopelman PG, Lefèbvre P, Reeder $\mathrm{BA}$. Dose-response issues concerning physical activity and health: an evidence-based symposium. Med Sci Sports Exerc. 2001;33(6 Suppl):S351-8.

3. World Health Organization. Global status report on noncommunicable diseases 2014: attaining the nine global noncommunicable diseases targets; a shared responsability. Geneva: World Health Organization; 2014. [acessed 2018 Sep 7]. Available from: http://www.who.int/nmh/publications/ ncd-status-report-2014/en/

4. Nocon M, Hiemann T, Müller-Riemenschneider F, Thalau F, Roll S, Willich SN. Association of physical activity with all-cause and cardiovascular mortality: a systematic review and meta-analysis. Eur J Cardiovasc Prev Rehabil. 2008;15(3):239-46.

5. Mancia G, Fagard R, Narkiewicz K, Redón I, Zanchetti A, Böhm M, et al; Task Force Members. 2013 ESH/ESC Guidelines for the management of arterial hypertension: the Task Force for the management of arterial hypertension of the European Society of Hypertension (ESH) and of the European Society of Cardiology (ESC). J Hypertens. 2013;31(7):1281-357.
6. Vasan RS, Larson MG, Leip EP, Evans |C, O'Donnell C|, Kannel WB, et al. Impact of high-normal blood pressure on the risk of cardiovascular disease. N Engl J Med. 2001;345(18):1291-7.

7. Cornelissen VA, Smart NA. Exercise training for blood pressure: a systematic review and meta-analysis. J Am Heart Assoc. 2013;2(1):e004473.

8. Whelton SP, Chin A, Xin X, He J. Effect of aerobic exercise on blood pressure: a meta-analysis of randomized, controlled trials. Ann Intern Med. 2002;136(7):493-503.

9. Bezerra P, Rodrigues LP, Ayan C, Cancela JM. The influence of winter and summer seasons on physical fitness in aged population. Arch Gerontol Geriatr. 2018;76:80-4

10. Cooper $\mathrm{KH}$. A means of assessing maximal oxygen intake. Correlation between field and treadmill testing. JAMA. 1968;203(3):201-4.

11. Cahalin LP, Mathier MA, Semigran MJ, Dec GW, DiSalvo TG. The six-minute walk test predicts peak oxygen uptake and survival in patients with advanced heart failure. Chest. 1996;110(2):325-32 
12. Johnson BT, MacDonald HV, Bruneau ML Jr, Goldsby TU, Brown JC, Huedo-Medina TB, et al. Methodological quality of meta-analyses on the blood pressure response to exercise: a review. J Hypertens. 2014;32(4):706-23.

13. Pescatello LS, MacDonald HV, Lamberti L, Johnson BT. Exercise for hypertension: a prescription update integrating existing recommendations with emerging research. Curr Hypertens Rep. 2015;17(11):87.

14. Torija Archilla A, Pérez González J, Sarmiento Ramírez Á, Fernández Sánchez E, González Ruiz JR, Guisado Barrilao R. Effects of a recreational general physical activity program with short term and moderate intensity of blood pressure and other cardiovascular risk factors in hypertensive patients over 50 years old. Aten Primaria. 2017;49(8):473-83.

15. Kawasaki T, Sullivan CV, Ozoe N, Higaki H, Kawasaki J. A long-term, comprehensive exercise program that incorporates a variety of physical activities improved the blood pressure, lipid and glucose metabolism, arterial stiffness, and balance of middle-aged and elderly lapanese. Hypertens Res. 2011;34(9):1059-66.

16. Linderman GC, Lu J, Lu Y, Sun X, Xu W, Nasir K, et al. Association of body mass index with blood pressure among 1.7 million chinese adults. JAMA Netw Open. 2018;1(4):e181271.

17. Tomás MT, Galán-Mercant A, Carnero EA, Fernandes B. Functional capacity and levels of physical activity in aging: a 3-year follow-up. Front Med (Lausanne). 2018;4:244.
18. Du H, Newton PJ, Salamonson Y, Carrieri-Kohlman VL, Davidson PM. A review of the six-minute walk test: its implication as a self-administered assessment tool. Eur J Cardiovasc Nurs. 2009;8(1):2-8.

19. Araújo RF, Serpeloni EC, Vaz ER, Borges RS, Silva AM, Minderico CS, et al. Cardiovascular fitness and cardiovascular risk factors among obese men and women aged 58 years and older, in Portugal. Rev Med Chil. 2012;140(9):1164-9.

20. Enright PL, McBurnie MA, Bittner $V$, Tracy RP, McNamara R, Arnold A, et al; Cardiovascular Health Study. The 6-min walk test: a quick measure of functional status in elderly adults. Chest. 2003;123(2):387-98.

21. Denehy L, Skinner EH, Edbrooke L, Haines K, Warrillow S, Hawthorne G, et al. Exercise rehabilitation for patients with critical illness: a randomized controlled trial with 12 months of follow-up. Crit Care. 2013;17(4):R156.

22. Bautmans I, Lambert M, Mets T. The six-minute walk test in community dwelling elderly: influence of health status. BMC Geriatr. 2004;4:6.

23. Mann S, Beedie C, Jimenez A. Differential effects of aerobic exercise, resistance training and combined exercise modalities on cholesterol and the lipid profile: review, synthesis and recommendations. Sport Med. 2014;44(2):211-21.

24. Bird SR, Hawley JA. Update on the effects of physical activity on insulin sensitivity in humans. BMJ Open Sport Exerc Med. 2017;2(1):e000143.

25. Hibler EA, Sardo Molmenti CL, Dai Q, Kohler LN, Warren Anderson S, Jurutka PW, et al. Physical activity, sedentary behavior, and vitamin D metabolites. Bone. 2016;83:248-55 